\title{
Rising Obesity and Breast Cancer Screening
}

\author{
Maryam Nemati Shafaee ${ }^{1 *}$ and Andrea Gerberding ${ }^{2}$ \\ ${ }^{1}$ Assistant Professor, Lester and Sue Smith Breast Cancer, Baylor College of Medicine, USA \\ ${ }^{2}$ Medical Student at Baylor College of Medicine, USA
}

Submission: April 29, 2018; Published: May 07, 2018

*Corresponding author: Maryam Nemati Shafaee, Assistant Professor, Lester and Sue Smith Breat Cancer, Baylor College of Medicine, USA, Tel: +1 713-798-1630; Email: maryshafaee@gmail.com

\section{Short Communication}

The epidemic of rising obesity in the United States has opened the Pandora's Box regarding the effects of obesity, defined as $\mathrm{BMI} \geq 30 \mathrm{~kg} / \mathrm{m}^{2}$, on various disease processes. According to the Centers for Disease Control and Prevention (CDC), the prevalence of obesity among US adults aged 20+ between 2011-2014 was $36.5 \%$. This number is even higher in women ages $40-59$ and $60+$, with reported prevalence of $42.1 \%$ and $38.8 \%$, respectively [1]. The association of increased cancer incidence with increasing BMI is well documented, and commonly associated cancers include endometrial cancer, ovarian cancer, and breast cancer in postmenopausal women, adenocarcinoma of the esophagus, kidney cancer, leukemia, multiple myeloma, pancreatic cancer, and non-Hodgkin's lymphoma [2]. Interestingly, endometrial and breast cancers are both estrogen-receptive, and the increased incidence of these cancers in obese women is related to an abnormal increase in the production of estrogen. The enzyme aromatase is found in adipose tissue, and is responsible for converting androgen to estrogen [3]. In premenopausal obese women, this would lead to an increased quantity of circulating estrogen; in postmenopausal obese women, this would result in ectopic production of estrogen. The treatment of breast cancer has classically involved the utilization of estrogen antagonists and aromatase inhibitors, further indicting estrogen in the development and progression of breast cancer.

The gold standard screening tool for breast cancer is mammography. Guidelines regarding initial age and subsequent frequency of screening mammograms vary by reporting body, but they all roughly agree that screening should begin between ages 40-50 and should be repeated every 1-2 years [4]. The purpose of screening mammography is to detect small malignant tumors while they are still asymptomatic. There has been an increase in the detection of small tumors $(<2$ $\mathrm{cm}$ ) and subsequent decrease in the number of large tumors detected with an associated reduction in mortality attributed to widespread screening mammography [5]. However, women who are obese are less likely to adhere to standard mammography guidelines [6]. Many obese women reported cancelling cancer screening appointments for various reasons including perceived negative judgment from physicians because of their obesity, as well as embarrassment about weight [7]. To further compound the decreased breast cancer screening in obese women, the technical difficulties of imaging a larger breast may make mammography less effective in these women. Weight and size limitations of equipment, excessive mobility of the breast tissue, and limits in the imaging window of the x-ray machine all contribute to the decreased efficacy of mammograms in the detection of small breast lesions in obese women [8]. Whether biennial mammographic screening confers the same benefit in obese women compared to women with normal BMI has been questioned in a recent study, where cancers detected within 2 years of the screening mammogram were larger and associated with worse prognosis in women with high BMI.

More frequent screening mammography may be necessary in obese women to achieve the same detection rate of small tumors as women with normal BMI based on this report [9]. Obesity is a risk factor both for the development of breast cancer, as well as poor outcomes after breast cancer diagnosis [10]. The rate of obesity is on the rise around the world [11]. Breast cancer is the most common malignancy among women in the developed as well the developing countries. Mammographic screening may not be as effective for detection of early breast cancers among obese women compared to women with normal BMI. Additionally, many studies report disparities with regard to adherence to mammographic screening among obese women. The guidelines of biennial mammographic screening may not be as effective0020among obese women compared to women with normal BMI and more frequent screening may be necessary. It is therefore imperative that future efforts towards breast cancer prevention take into the account the growing public health burden of obesity. Raising awareness among healthcare providers regarding issues specific to obesity and breast cancer 
screening, compounded with better understanding of the unique needs of obese patients, such as larger gown sizes and wheelchair accessible facilities may deem beneficial.

Educating patients of risks associated with an increased $\mathrm{BMI}$, and reinforcing life style habits that aid in achieving normal weight is an important milestone towards individual breast cancer risk reduction. This step should be approached with compassion to encourage obese patients to continue seeking appropriate screening measures regardless of their weight loss efforts. An upfront conversation between the physician and patients about common challenges experienced by obese patients during mammography, and how to address these challenges, may go a long way in assuaging some of the anxiety obese women may experience in anticipation of receiving a mammogram. In the end, the goal of healthcare is to educate patients on best practices, and then adapt these practices to meet the patient where they're at, with the purpose of creating a healthier society.

\section{Refernces}

1. Ogden CL, Carroll MD, Fryar CD, Flegal KM (2015) Prevalence of Obesity Among Adults and Youth: United States, 2011-2014. NCHS Data Brief p. 1-8.

2. Reeves GK, Pirie K, Beral V, Green J, Spencer E, et al. (2007) Cancer incidence and mortality in relation to body mass index in the Million Women Study: cohort study. BMJ 335: 1134.
3. Nelson LR, Bulun SE (2001) Estrogen production and action. J Am Acad Dermatol 45: S116-124.

4. Centers for Disease Control and Prevention (2017) Breast Cancer Screening Guidelines for Women.

5. Welch HG, Prorok PC, O’Malley AJ, Kramer BS (2016) Breast Cancer Tumor Size, Overdiagnosis, and Mammography Screening Effectiveness. N Engl J Med 375: 1438-1447.

6. Cohen SS, Palmieri RT, Nyante SJ, Koralek DO, Kim S, et al. (2008) Obesity and screening for breast, cervical, and colorectal cancer in women: a review. Cancer 112: 1892-1904.

7. Friedman AM, Hemler JR, Rossetti E, Clemow LP, Ferrante JM (2012) Obese women's barriers to mammography and pap smear: the possible role of personality. Obesity (Silver Spring) 20: 1611-1617.

8. Destounis S, Newell M, Pinsky R (2011) Breast imaging and intervention in the overweight and obese patient. AJR Am J Roentgenol 196: 296-302.

9. Strand F (2017) Large Breast Cancers in Women Attending Regular Screening: Risk Factors and Implications for Prognosis. Radiological Society of North America annual meeting, Chicago, USA.

10. Picon Ruiz M (2017) Obesity and Adverse Breast Cancer Risk and Outcome: Mechanistic Insights and Strategies for Intervention. 67(5): 378-397.

11. Agha M, Agha R (2017) The Rising Prevalence of Obesity: Part A: Impact on Public Health. Int J Surg Oncology 2(7): e17.

\section{Your next submission with Juniper Publishers} will reach you the below assets 